Supplement of The Cryosphere, 12, 3511-3534, 2018

https://doi.org/10.5194/tc-12-3511-2018-supplement

(C) Author(s) 2018. This work is distributed under

the Creative Commons Attribution 4.0 License.

(c) (1)

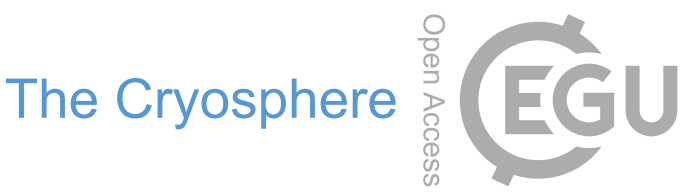

Supplement of

\title{
Exploration of Antarctic Ice Sheet 100-year contribution to sea level rise and associated model uncertainties using the ISSM framework
}

Nicole-Jeanne Schlegel et al.

Correspondence to: Nicole-Jeanne Schlegel (schlegel@jpl.nasa.gov)

The copyright of individual parts of the supplement might differ from the CC BY 4.0 License. 
Table S1. Mean melt rate estimates derived from satellite (2003-2008, Rignot et al. (2013)) and ocean model simulations with standard deviation (2004-2008) for each GP. We also include mean melt rate estimates at the grounding line, averaged over the control run period (2004-2013) for each GP. The last two columns list the mean cavity daily maximum temperature (cavity Tmax) and the mean daily maximum boundary temperature (Tmax) for 2004-2008. Cavity Tmax is defined as the mean maximum daily temperature within all ice shelf cavities of a particular GP. Tmax is defined as the mean maximum daily temperature below the thermocline and off of the continental shelf, and consists of Warm Deep Water in the Weddell Sea and Circumpolar Deep Water elsewhere. In derivation of our IB maximum melt multipliers, we assume that the difference between Tmax and cavity Tmax is representative of the maximum heat that could enter the cavity and potentially contribute to extreme melt rates (see Appendix Sect. A).

\begin{tabular}{lccccc}
\hline $\begin{array}{l}\text { Geographic } \\
\text { partition } \\
\text { number }\end{array}$ & $\begin{array}{c}\text { Rignot et } \\
\text { al., } 2013 \\
\text { rate }\left(\mathrm{m} \mathrm{y}^{-1}\right)\end{array}$ & $\begin{array}{c}\text { Mean } \\
\text { rate }\left(\mathrm{m} \mathrm{y}^{-1}\right)\end{array}$ & $\begin{array}{c}\text { Mean Grounding } \\
\text { Line Melt } \\
\text { rate }\left(\mathrm{m} \mathrm{y}^{-1}\right)\end{array}$ & $\begin{array}{c}\text { Mean Cavity } \\
\text { Temperature Maximum } \\
\left({ }^{\circ} \mathrm{C}\right)\end{array}$ & $\begin{array}{c}\text { Mean } \\
\text { Temperature Maximum } \\
\left({ }^{\circ} \mathrm{C}\right)\end{array}$ \\
\hline 1 & 1.1 & $0.94 \pm 0.61$ & $0.38 \pm 0.52$ & -1.5 & 0.68 \\
2 & 2.78 & $2.77 \pm 0.36$ & $1.59 \pm 1.78$ & +0.3 & 2.32 \\
3 & 2.6 & $3.28 \pm 1.78$ & $2.51 \pm 2.37$ & -0.3 & 2.27 \\
4 & 11.3 & $11.83 \pm 2.35$ & $7.76 \pm 7.04$ & +0.2 & 2.27 \\
5 & 2.15 & $3.48 \pm 0.24$ & $2.68 \pm 1.83$ & +0.1 & 2.12 \\
6 & 0.85 & $0.86 \pm 0.14$ & $0.18 \pm 0.28$ & -1.8 & 0.76 \\
7 & 0.3 & $0.37 \pm 0.06$ & $0.76 \pm 2.24$ & -1.7 & 0.67 \\
8 & 0.4 & $0.4 \pm 0.03$ & $0.50 \pm 0.47$ & -1.5 & 0.64 \\
9 & 0.27 & $0.38 \pm 0.16$ & $0.26 \pm 0.55$ & -1.6 & 0.47 \\
$10 / 11$ & 1.74 & $1.56 \pm 0.56$ & $0.38 \pm 1.65$ & -1.3 & 0.97 \\
12 & 2.18 & $1.95 \pm 0.65$ & $0.57 \pm 8.89$ & -1.9 & 0.92 \\
13 & 0.56 & $0.63 \pm 0.30$ & $0.81 \pm 1.32$ & -1.6 & 1.19 \\
19 & 2.35 & $2.51 \pm 0.64$ & $1.34 \pm 1.73$ & -1.2 & 1.34 \\
24 & 6.83 & $0.89 \pm 0.74$ & $0.33 \pm 0.82$ & -1.7 & 2.00 \\
25 & 0.6 & $0.64 \pm 0.16$ & $1.80 \pm 3.26$ & -1.8 & 2.17 \\
26 & 1.95 & $1.56 \pm 1.61$ & $0.86 \pm 5.34$ & -1.9 & -1.1 \\
27 & 4.1 & $3.84 \pm 1.05$ & $3.10 \pm 2.96$ & &
\end{tabular}



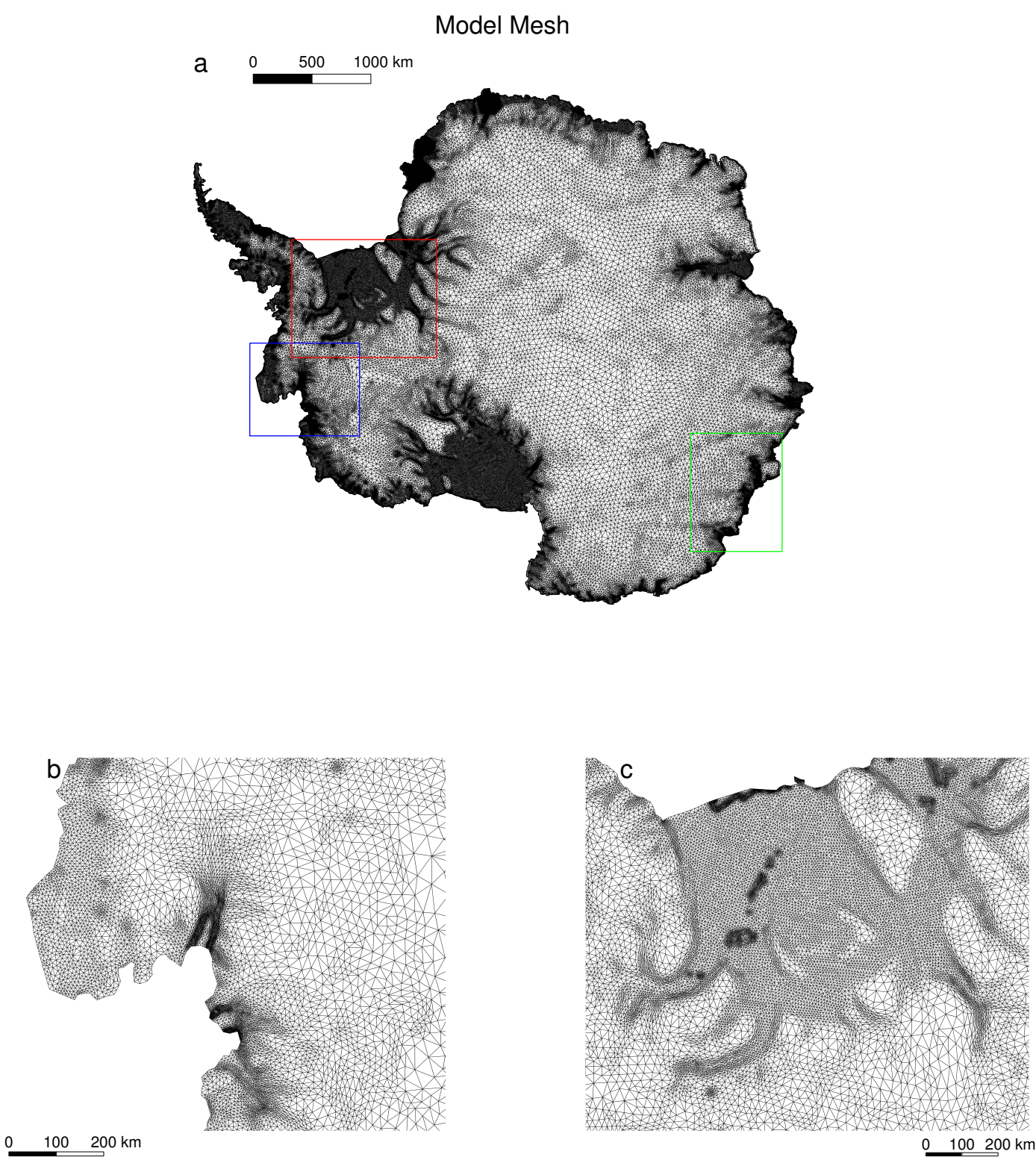

Figure S1. The ISSM Antarctica mesh for (a) the entire ice sheet, (b) Amundsen Sea sector (outlined in blue in (a)), and (c) Ronne Ice Shelf region (outlined in red in (a)). The green box shows the Wilkes Land (including Moscow University Ice Shelf and Totten Glacier) region (used in Fig. S5e,f). 
a

\section{Sea Level Contribution for sensitivity runs}

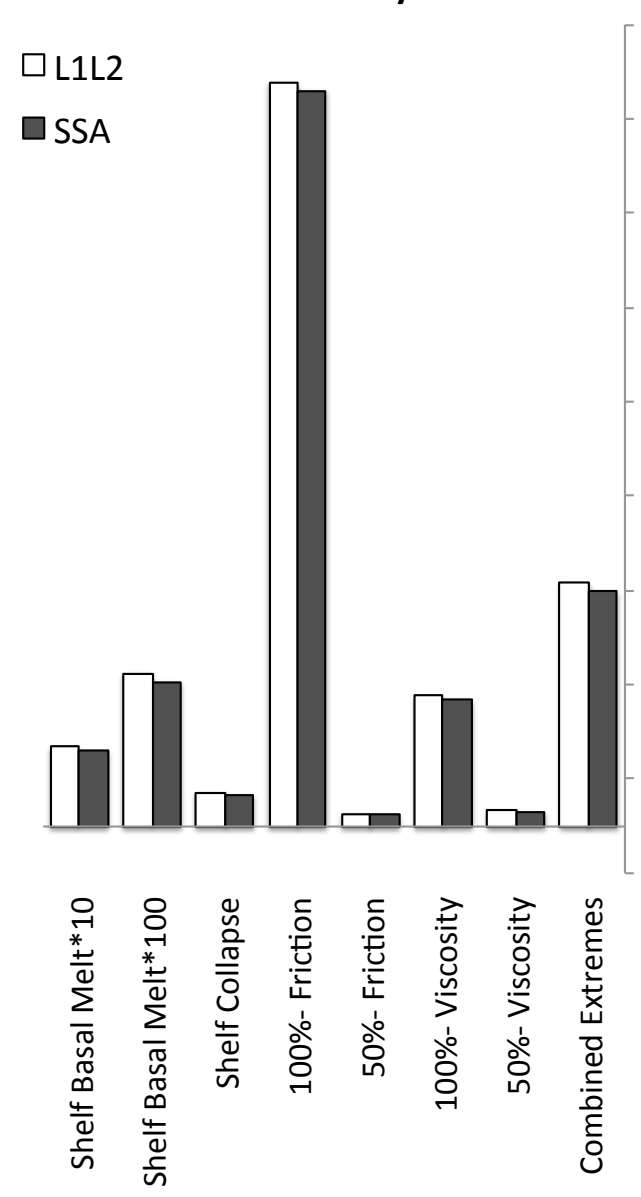

\section{b Sea Level Contribution for melt sensitivity runs - Control bias}

曰\% Difference

6.5

5.5

4.5

$\underset{\mathfrak{E}}{\breve{u}}$

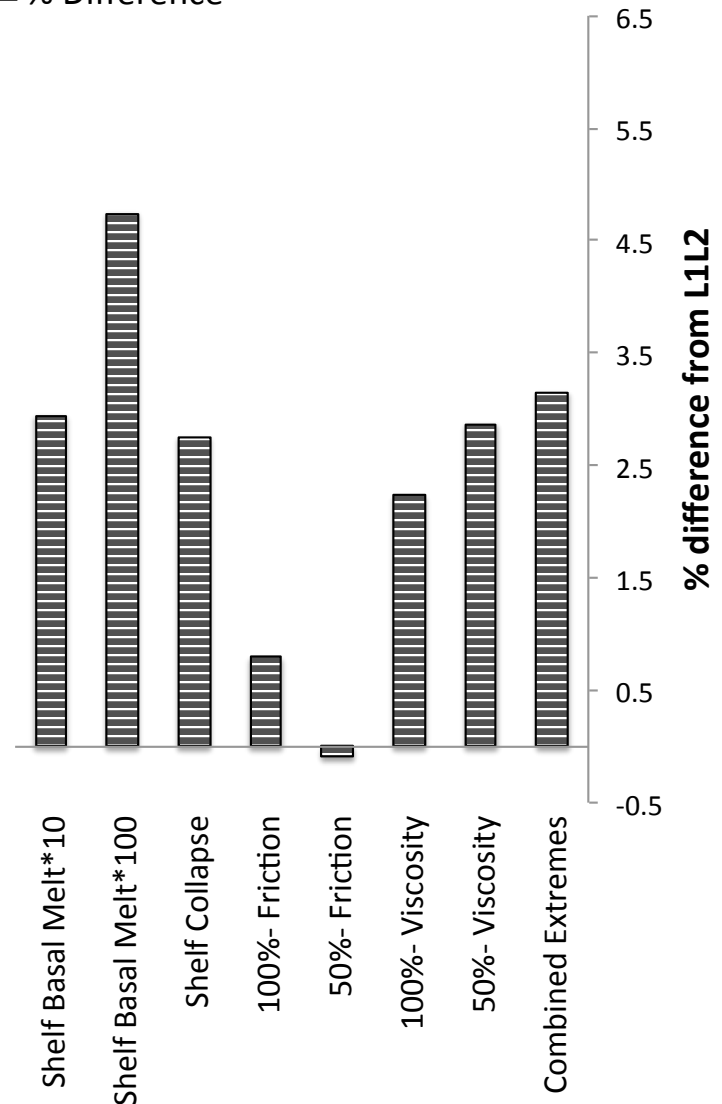

1.5

0.5

$-0.5$

Figure S2. Mean SLE contribution (m) from single 100-year simulations, under various extreme forcing, including uniform multiplication of ice shelf basal melt by 10 and 100 ; collapse of all ice shelves; uniform reduction of basal friction by $50 \%$ and $99.99 \%$; uniform reduction of ice viscosity by $50 \%$ and $99.99 \%$; and a combination of uniform extreme forcing (ice shelf basal melt multiplied by 10 , basal friction decreased by $60 \%$, ice viscosity decreased by $40 \%$, and accumulation decreased by $50 \%$ ). The combination results shown are equivalent to the max endmember of a UB 1-partition sampling experiment. (a) Comparison of results for these sensitivity experiments run for two different stress balance equations: L1L2 and SSA. (b) Percent difference between SSA and L1L2 simulations, corrected for the bias in their respective control runs. Note that the difference between all runs after 100 years is less than $5 \%$. 

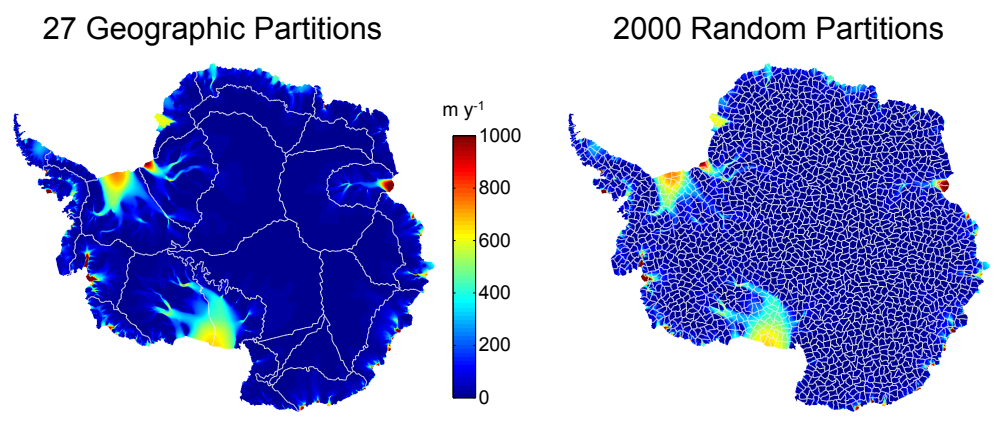

500 Random Partitions
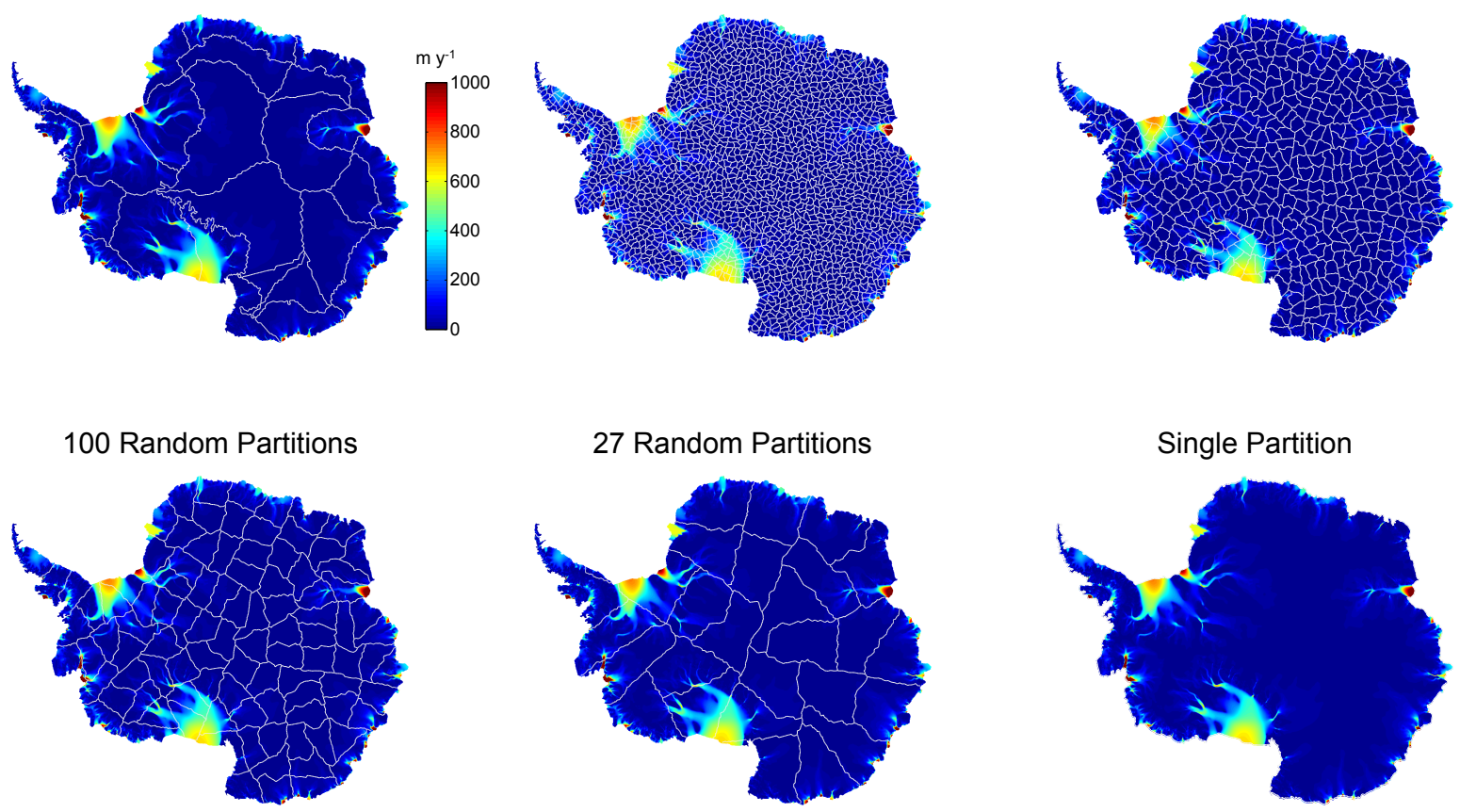

Figure S3. Various partition configurations corresponding to the sampling experiments featured in Fig. 2, plotted over initial modeled surface ice velocities ( $\mathrm{m} \mathrm{y}^{-1}$ ). 


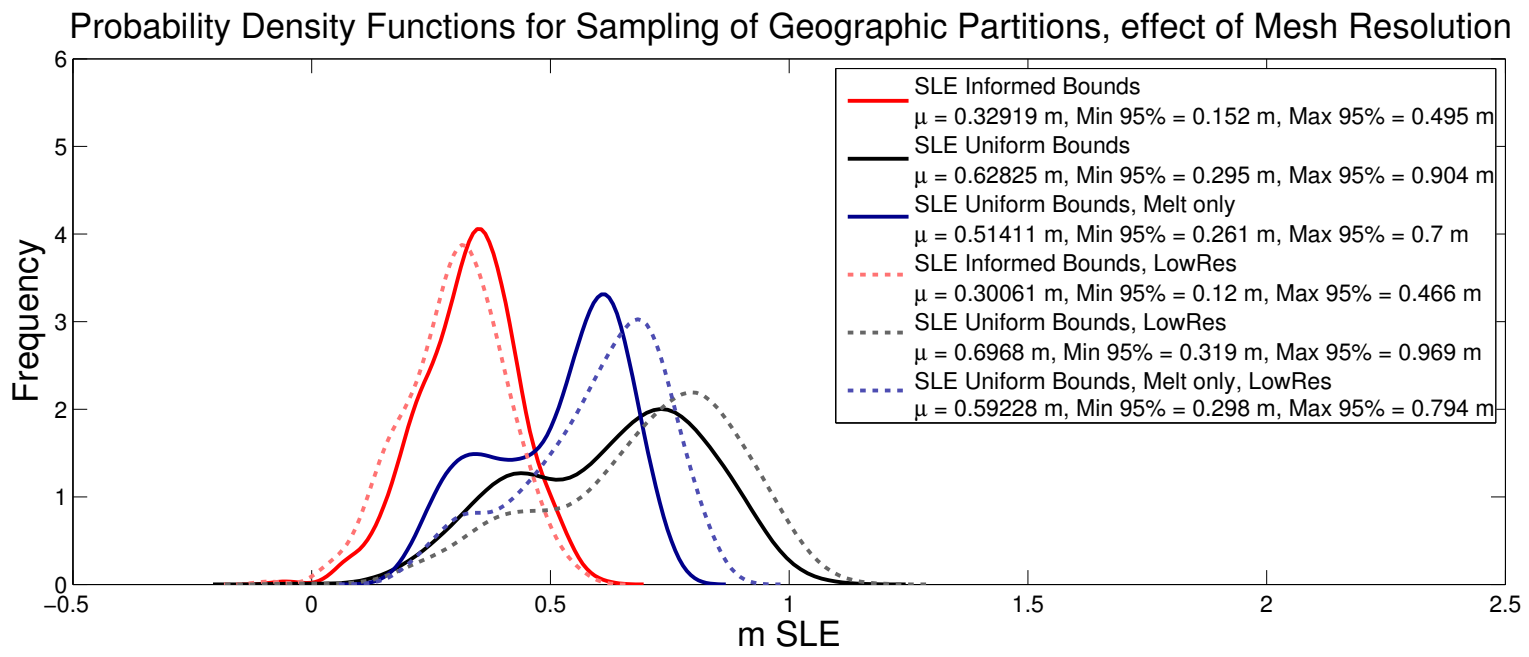

Figure S4. Comparison of SLE (m) PDFs for simulations performed with high (solid lines) and low (LowRes, dotted lines) mesh resolution. Ensemble runs of 800 simulations run with GP partitioning include UB combined variable (black) experiments, IB combined variable (red) experiments, and the UB melt only (dark blue) experiments. 

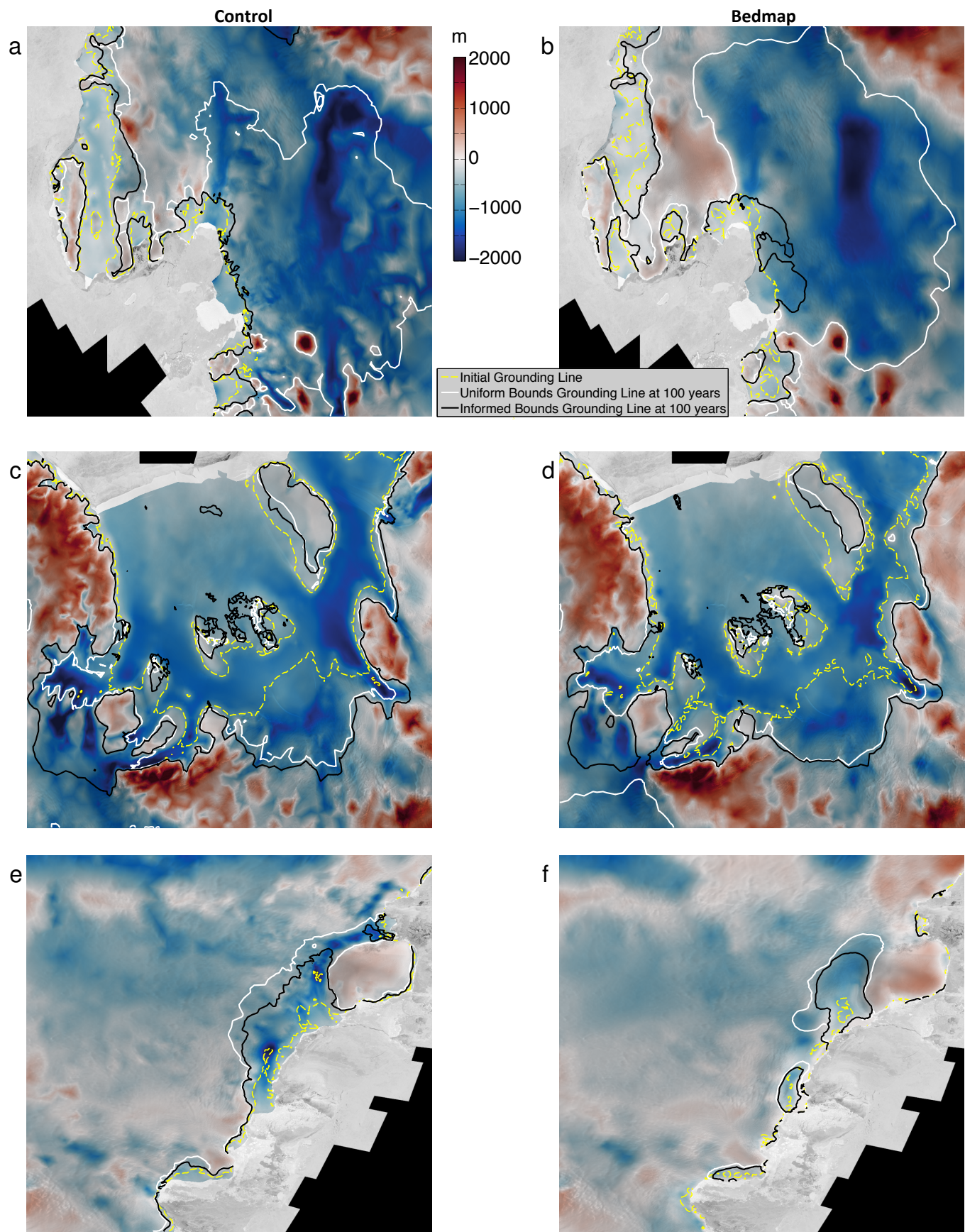

Figure S5. Regional bed topography used in ISSM for simulations performed with the Bedmap2/MC (left panels) and Bedmap1 bedrock topographies (right panels). Regions included are: (a,b) Amundsen Sea, particularly Pine Island and Thwaites Glaciers (blue inset in Fig. S1), (c,d) Ronne Ice Shelf and ice streams (red inset in Fig. S1) and (e,f) Wilkes Land, including Moscow University Ice Shelf and Totten Glacier (green inset in Fig. S1). Yellow dashed lines are the initial grounding line positions. White solid lines and black solid lines are respectively the grounding line positions for the single extreme forcing highlighted in Fig. S6 for the UB and IB combined variable runs. 


\section{Sea Level Contribution per region for extreme scenario 200 -year sensitivity runs}
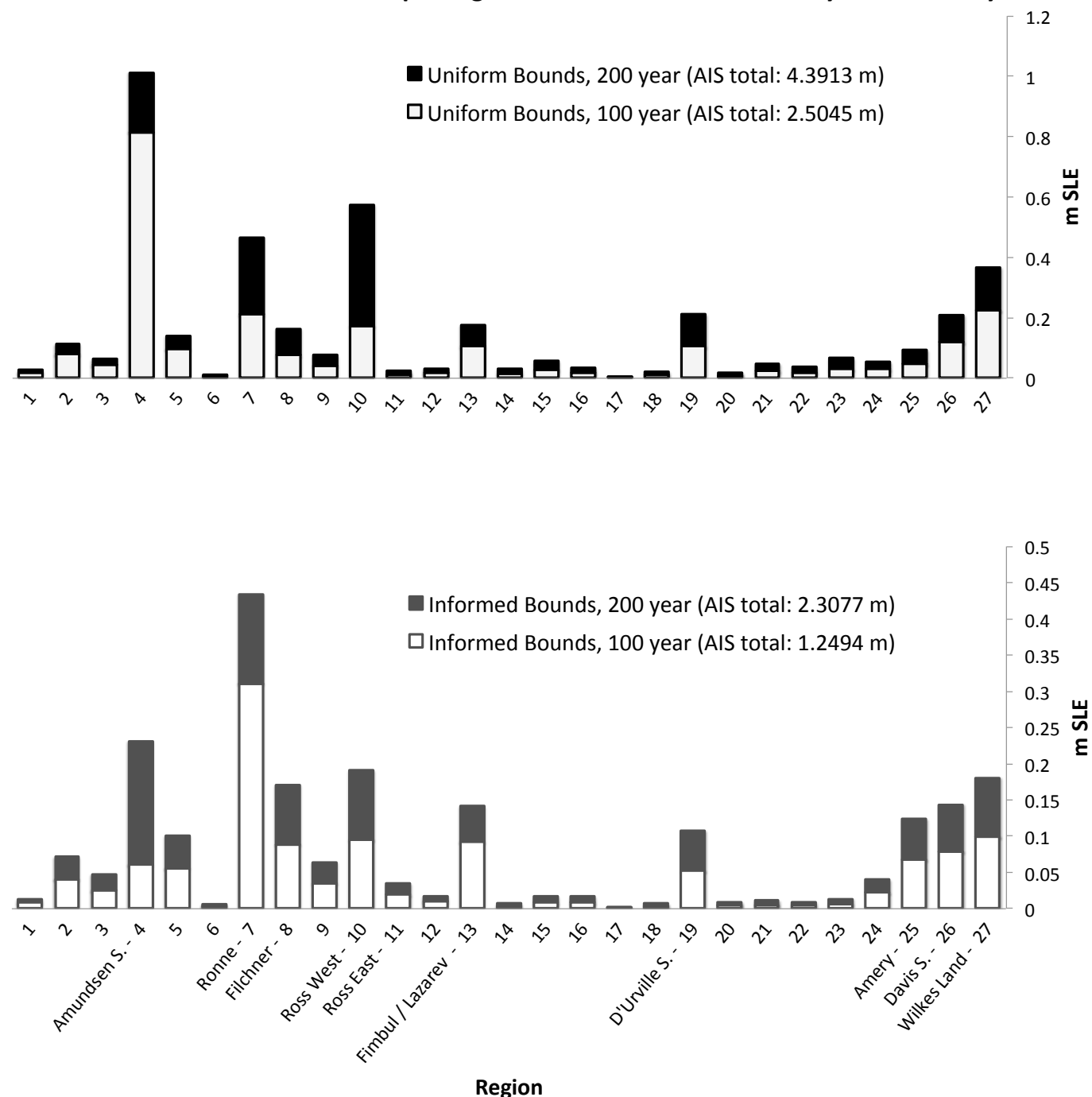

Figure S6. SLE contribution (m, with respect to a control run) from single AIS runs (200-year simulations) forced with extreme warming from the UB and IB experiments. Top: extreme endmember from the UB experiment (combination of ice shelf basal melt multiplied by 10 , basal friction decreased by $60 \%$, ice viscosity decreased by $40 \%$, and accumulation decreased by 50\%). Bottom: extreme endmember from the IB experiment (combination of parameter values set at informed extreme bounds, determined regionally). These two runs represent the regional SLE contribution far right endmember (maximum possible contribution) of the UB 1-partition (UB_1) and IB geographic partition (IB_27GP) sampling experiments. (See Table 1 and Table 2 respectively for details about simulation bounds.) 